\title{
Excellence in Sales Management
}

Rund zehn Prozent aller Beschäftigten arbeiten im Vertrieb. Fast ein Viertel der Mitarbeiter deutscher Unternehmen entfällt auf den Vertriebsbereich. Verglichen mit anderen Unternehmensbereichen besitzt der Vertrieb mit 61 Prozent die größte Bedeutung für den Geschäftserfolg. Als wichtigstes Bindeglied zum Kunden besitzt der Vertriebsmitarbeiter den größten Einfluss auf die Loyalität des Kunden. Längst hat sich auch in der Marketingforschung der Vertrieb von einem Teilbereich des Marketings zu einer eigenen Forschungsdisziplin entwickelt.

Kernherausforderungen im Vertrieb sind von vielfältiger Natur: Sie reichen von der Identifikation von Erfolgsfaktoren in der Kundeninteraktion über das Talent Management bis zu einem erfolgreichen Management der Digitalisierung des Vertriebs.

Die Beiträge dieser Ausgabe adressieren diese Themenfelder, um Anhaltspunkte und Hilfestellungen zu liefern, um den Kernherausforderungen im Vertriebsbereich begegnen zu können. Ziel der Ausgabe ist es, Ansätze für ein professionelles Vertriebsmanagement und aktuelle Forschungsergebnisse zu identifizieren, die zur Exzellenz im Vertriebsmanagement beitragen. Leser können sich über hochkarätige Beiträge aus Wissenschaft und Praxis freuen.

Auf Basis einer aktuellen Studie von 510 Führungskräften im Vertrieb stellen wir im Leitartikel Mythen und Fakten gegenüber und identifizieren vor allem einen drohenden, stark ansteigenden Fachkräftemangel als zukünftige Herausforderung für den Vertriebsbereich. Mit dem „Sales Management“ Master der Ruhr-Universität Bochum wird ein Ansatz dargestellt, um dem drohenden Fachkräftemangel im Vertrieb effizient entgegenzuwirken.

Ansätze zu einem erfolgreichen Beziehungsmanagement liefern die Beiträge „Professionalität im Vertrieb“ (Belz, Dannenberg), „Mit Kundensegmentierung zur effizienten Vertriebssteuerung“ (Ahlers), „Key Account Management Selling or Providing Services ... or both?“ (Ivens, Niersbach, Pardo) und „Kundenstatus im Vertrieb: Dos and Don’ts“ (Hammerschmidt, Klein, Wetzel) dieser Ausgabe.

Auf die Rolle der Digitalisierung wird in dieser Ausgabe der Marketing Review St. Gallen in den Beiträgen „Technologieakzeptanz von Verkäufern als Herausforderung“ (Spreer, Gut-

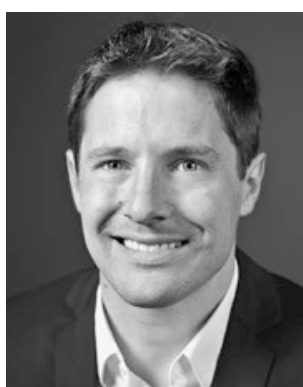

Prof. Dr. Christian Schmitz

Universitätsprofessor für Vertriebsmanagement, Sales \& Marketing Department, Ruhr-Universität Bochum

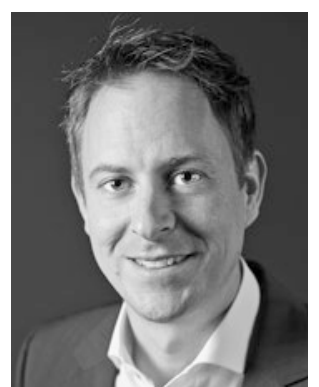

Prof. Dr. Jan Wieseke Universitätsprofessor für Vertriebsmanagement, Sales \& Marketing Department, Ruhr-Universität Bochum

knecht), „Digital Sales Excellence - Systematischer Einsatz neuer Technologien im Vertrieb“ (Binckebanck) und „SocialMedia-Kompetenz: Der vergessene Erfolgsfaktor im modernen Vertrieb“ (Bowen, Haas) näher eingegangen.

Darüber hinaus verrät Reiner Strecker, Mitglied der Unternehmensleitung und persönlich haftender Gesellschafter der Vorwerk \& Co. KG, im Gespräch mit uns, wie das Unternehmen sein Vertriebskonzept in den letzten Jahren transformiert hat und welche Risiken und Chancen damit verbunden sind.

Die Autoren aus Praxis und Wissenschaft zeigen in dieser Themenausgabe, wie sowohl theoretisch als auch praktisch Herausforderungen im Vertriebsmanagement angegangen werden können, um diese in Chancen zu verwandeln.

An dieser Stelle möchten wir uns bei Frau Janina-Vanessa Schneider, M.Sc. herzlich bedanken. Durch die Arbeit als Koordinatorin dieser Ausgabe konnten wir herausragende Praktiker sowie Wissenschaftler für einen Beitrag gewinnen.

Wir wünschen allen Lesern viel Freude bei der Lektüre und viele wertvolle Impulse für das eigene Vertriebsmanagement!

Herzliche Grüße aus Bochum
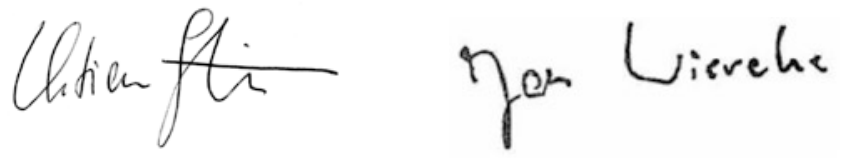